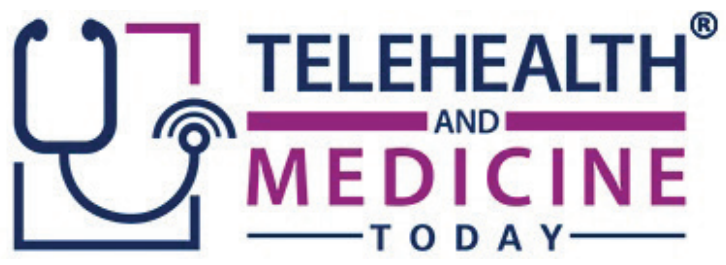

\title{
Nurse Practitioners and Virtual Care: A 50-State Review of APRN Telehealth Law and Policy
}

\author{
Kelli M. Garber, ${ }^{1}$ Katherine E. Chike-Harris ${ }^{2}$
}

Author: ${ }^{1}$ Medical University of South Carolina Center for Telehealth, USA; ${ }^{2}$ Medical University of South Carolina College of Nursing, USA

Corresponding Author: Kelli Garber, Email: garberk@musc.edu

Keywords: APRN, Legislation, Medical Practice Acts, Nurse Practice Acts, Nurse Practitioner, Policy, Regulation, Telehealth, Telemedicine Acts, Telemedicine Advisory Opinions, Telemedicine Board of Medicine, Telemedicine Board of Nursing, Telemedicine Position Statements

Category: Review Article

The healthcare industry is bracing for a predicted shortage of primary care physicians at a time when the telehealth industry is predicted to explode. Advance practice registered nurses (APRNs), who combine clinical expertise with an added emphasis on disease prevention and health management, have long been providing high-quality healthcare in the United States and will likely play a key role in assisting to alleviate this anticipated shortage. Approximately $86 \%$ of $A P R N$ s are certified in an area of primary care, and the workforce continues to grow with over 26,000 new APRNs completing their academic programs in 2017. Empowering APRNs to provide care via telehealth will extend the reach of their expertise and further expand access to care. Before providing care via telehealth, APRNs must be well versed in the laws, regulations, and policies affecting their practice when using this modality, especially since these can vary significantly between states. To this end, a 50-state review of APRN legislation, advisory opinions, policy statements, and telehealth legislation as it pertains to APRNs was conducted. The findings illustrate a wide array of APRN telehealth policies and regulations, ranging from no APRN telehealth provisions to detailed guidelines established in statute. State-by-state findings are summarized while identifying the various resources that should be considered when reviewing APRN telehealth practice policy. Recommendations to foster telehealth adoption by APRNs through legislative means are also provided. 
$\mathrm{O}$ ne of the earliest references to the use of telecommunication technologies in healthcare involves connecting a medical station staffed with nurse clinicians at Boston's Logan Airport to Massachusetts General Hospital in 1963. ${ }^{1}$ Since then, telehealth has become a rapidly growing field in the healthcare community where advanced practice registered nurses (APRNs) have become an integral part of the healthcare team.

The number of APRNs in the United States is growing, with a predicted $31 \%$ rise in employment by $2026 .{ }^{2}$ With over 270,000 APRNs currently licensed in the United States, ${ }^{3}$ and the predicted growth of the profession paralleling the growth of the telehealth industry, it can be inferred that these APRNs will likely find themselves engaging in telehealth in one form or another to expand the reach of care beyond the walls of the traditional office or clinic. Growth in the telehealth industry is demonstrated by the increased utilization of telemedicine visits among rural Medicare beneficiaries. ${ }^{4}$ Telemedicine utilization increased from 7,015 visits in 2004 to 107,955 visits in 2013, indicating an annual Medicare visit growth rate of $28 \%$ between 2004 and $2013 .{ }^{4}$ With such expanded use, increased opportunities can occur for all healthcare providers, while increasing access to care for patients, especially those in the rural and underserved areas.,

With increased utilization of APRNs within the telehealth provider role, it is important that APRNs are cognizant of several professional practice issues, such as federal and state laws and regulations, credentialing and privileging, malpractice coverage, position statements by governing bodies, established guidelines, and reimbursement policies. ${ }^{7}$ Although many factors must be considered, the focus of this article will be on state laws and regulations affecting APRN telehealth practice.
Telehealth policy is impacted by many healthrelated government programs, laws, regulations, and policies. It is crucial that APRNs thoroughly evaluate the state laws governing their practice in both the state where the patient is located and the state where the provider is located. State policies vary significantly, and no two states are alike in their definition of telehealth. Some states have established laws related to telehealth, while others have addressed definitions, reimbursement policies, licensure requirements, and other issues in their Medicaid Program Guidelines. ${ }^{8}$ Variations in state laws pertaining to telehealth include differences in prescribing rules, telehealth consent requirements, establishment of a patient-provider relationship via telehealth, cross-state licensing, and identification of types of providers approved to utilize telehealth. In addition, depending on which state statute a telehealth law may modify, it may or may not apply to all healthcare providers. For example, the South Carolina Telemedicine Act signed into law on June 3, 2016 amended Title 40-Chapter 47 of the Code of Laws in South Carolina, which governs the practice of "Physicians and Miscellaneous Health Care Professionals."

This Act, however, did not address APRNs, nor did it modify the South Carolina Nurse Practice Act, necessitating new legislation to codify APRN telehealth practice. Moreover, an absence of a telehealth statute pertaining to an APRN may or may not be interpreted as permissible by the state medical or nursing boards. In fact, in 2017, APRNs in South Carolina were advised to cease providing care via telehealth until legislation could be enacted.

While the Center for Connected Health Policy and the American Telemedicine Association's State Policy Resource Center are outstanding resources for telehealth policy, ${ }^{10,11}$ to the authors' knowledge, there does not exist a resource that 
includes details of advisory opinions, position statements, or telenursing policy across the United States. This article provides a brief overview of the aforementioned topics to provide APRN telehealth providers a quick state-by-state comparison, as well as tips on how to locate APRN telehealth information for respective states.

\section{METHODS}

We performed an Internet search using Google, Firefox, and Chrome to locate telehealth information pertaining to healthcare providers. Various search terms were used in conjunction with each name of the 50 states: "telemedicine," "telemedicine laws," "telemedicine acts," "nurse practice acts," "telemedicine board of medicine," "medical practice acts," "telemedicine board of nursing," "APRN telemedicine advisory opinions," and "APRN telemedicine position statements" and the same utilizing the term "telehealth." The most recent 50-state review by the Center for Connected Health Policy's "State Telehealth Laws and Reimbursement Policies" was also used to identify legislation pertaining to APRNs and telehealth care. ${ }^{12}$

\section{RESULTS}

The findings summarized in Table 1 illustrate that most states have some telehealth guidelines, but the definition of telehealth varies, as well as the providers who can practice it. For example, the Alabama Board of Medical Examiners states that physicians can practice telemedicine within

Table 1. Summary of state telehealth positions in the United States

\begin{tabular}{|c|c|c|c|c|c|}
\hline State & $\begin{array}{c}\text { Nurse } \\
\text { Practice Act }\end{array}$ & $\begin{array}{c}\text { Medical } \\
\text { Practice Act }\end{array}$ & $\begin{array}{l}\text { Telehealth } \\
\text { Act }\end{array}$ & $\begin{array}{c}\text { APRN/Nursing } \\
\text { Advisory Opinions }\end{array}$ & $\begin{array}{c}\text { Telehealth Position } \\
\text { Statements }\end{array}$ \\
\hline Alabama & & & & & $*$ \\
\hline Alaska & & & \# & $*$ & \\
\hline Arizona & & & \# & & \\
\hline Arkansas & & & $*$ & & $*$ \\
\hline California & & & $*$ & $*$ & \\
\hline Colorado & $*$ & & $*$ & & \\
\hline Connecticut & & & $*$ & & \\
\hline Delaware & $*$ & & & & \\
\hline Florida & & & & & $*$ \\
\hline Georgia & & & $*$ & & \\
\hline Hawaii & $*$ & & $*$ & & \\
\hline Idaho & & & $*$ & & \\
\hline Illinois & & & $*$ & & \\
\hline Indiana & & & $*$ & & \\
\hline Iowa & & & & & $*$ \\
\hline Kansas & & & $*$ & & \\
\hline Kentucky & $*$ & & $*$ & & \\
\hline Louisiana & & & $\#$ & & \\
\hline
\end{tabular}

(Continued) 
Table 1 (Continued). Summary of state telehealth positions in the United States

\begin{tabular}{|c|c|c|c|c|c|}
\hline State & $\begin{array}{c}\text { Nurse } \\
\text { Practice Act }\end{array}$ & $\begin{array}{c}\text { Medical } \\
\text { Practice Act }\end{array}$ & $\begin{array}{l}\text { Telehealth } \\
\text { Act }\end{array}$ & $\begin{array}{l}\text { APRN/Nursing } \\
\text { Advisory Opinions }\end{array}$ & $\begin{array}{c}\text { Telehealth Position } \\
\text { Statements }\end{array}$ \\
\hline Maine & & & \# & & \\
\hline Maryland & & & $*$ & & \\
\hline Massachusetts & & & & & \# \\
\hline Michigan & * & & $*$ & & \\
\hline Minnesota & & & $*$ & & $*$ \\
\hline Mississippi & & & & & \# \\
\hline Missouri & $*$ & & $*$ & & \\
\hline Montana & & $\#$ & & & \\
\hline Nebraska & & $*$ & $*$ & & \\
\hline Nevada & & & $*$ & & \\
\hline New Hampshire & $*$ & & $*$ & $*$ & $*$ \\
\hline New Jersey & & & $*$ & & \\
\hline New Mexico & & & $*$ & & \\
\hline New York & & & $*$ & $*$ & $*$ \\
\hline North Carolina & & & \# & $*$ & $*$ \\
\hline North Dakota & & & \# & & \\
\hline Ohio & & & $*$ & $*$ & $*$ \\
\hline Oklahoma & & & \# & & $*$ \\
\hline Oregon & & & \# & & \\
\hline Pennsylvania & & & $*$ & $*$ & \\
\hline Rhode Island & & & $*$ & & \\
\hline South Carolina & $*$ & & $*$ & & \\
\hline South Dakota & & & \# & & \\
\hline Tennessee & & & $*$ & & \\
\hline Texas & & & $*$ & & \\
\hline Utah & & & $*$ & $*$ & $*$ \\
\hline Vermont & $*$ & & $*$ & & \\
\hline Virginia & & & $*$ & & \\
\hline Washington & & & $*$ & & \\
\hline West Virginia & & & $*$ & & $*$ \\
\hline Wisconsin & & & $*$ & & \\
\hline Wyoming & & & $*$ & $*$ & \\
\hline
\end{tabular}

Summary of state telehealth laws, acts, advisory opinions, and position statements, which are grouped under the term elements. Medical Practice Acts and Nurse Practice Acts: laws governing the practice of medicine and nursing, respectively, both of which are state specific; Telehealth Acts: laws governing the practice of telemedicine and are state specific; APRN/Nursing Advisory Opinions: a board's nonbinding interpretation of law directly related to nursing and APRN practice; telehealth position statements: an entity's (usually the state) reasons to support a particular viewpoint as it relates to the practice of telehealth. Blank entry: no telehealth element(s) found; *: presence of an element; \#: presence of an element, but does not directly affect APRNs. 
their scope of practice per Alabama Code $\S \S 34-$ 24-290 and the Rules of the Alabama Board of Medical Examiners. ${ }^{13}$ This law also includes the scope of practice of telemedicine for nonphysician providers, such as physician assistants, certified registered nurse practitioners, and certified nurse midwives. The Alabama Nurse Practice Act also contains a definition of telehealth nursing [Code of Ala. 1975, §§ 34-21-2(c) (21)], and a description of the laws and regulations relating to telenursing practice [Code of Ala. 1975, $\S \S 34-21-2,34-21-2$ (c) (21)]. ${ }^{14}$ Specifically mentioning telehealth in both the Rules of the Board of Medical Examiners and the Nurse Practice Act confirms that APRNs have the ability to practice telehealth within the state of Alabama.

In contrast, at the time of this publication, the North Dakota (ND) Board of Medicine defined a telemedicine licensee as "a physician or physician assistant licensed to practice in North Dakota," per ND Cent. Code § 50-0215-01 (para. 2). ${ }^{15}$ Unlike Alabama, ND's Nurse Practice Act does not include any mention of telehealth or telenursing, per ND Cent. Code $\S 43.12 .1 .{ }^{16}$ Additionally, the authors were unable to find any position statements or advisory opinions regarding APRN telehealth practice in ND through the Internet search. The lack of a specific statute for telehealth nursing, combined with no other telenursing findings, may suggest that in the state of ND only physicians or physician assistants are allowed to practice telemedicine and other nonphysician providers, such as APRNs, may be barred from telehealth. However, even though there is no specific statute specifying APRN telehealth practice, ND Cent. Code $\S 43-51.02$ allows the provision of healthcare services that are within the scope of practice of a profession or occupation, by any means that are regulated by the appropriate state board. ${ }^{17}$ The question remains as follows: Does ND Cent. Code $\S 43-51.02$ then "allow" APRNs to practice telemedicine in the state of ND as long as it aligns with their scope of practice?

\section{DISCUSSION}

The findings of the review reveal wide variations among states with regard to APRN practice and telehealth care. APRNs must review the telemedicine laws in the states where they practice with a critical eye to ensure that their practice falls within these regulations. Only nine states mention telehealth in their Nurse Practice Acts, while 39 have Telemedicine Acts. There are nine states with Advisory Opinions and 14 with Position Statements. Of those with Position Statements, two states address telenursing but do not specifically mention APRNs. When reviewing Telemedicine Acts, it is important to identify the prior legislation the telehealth act modifies, or whether telemedicine is a standalone statute. In some cases, these acts amend the physician practice act, while others amend health occupations or healing arts acts. It is important to focus specific attention on the language used within the act as well. Does the act refer to "physicians," "providers," or "practitioners," or does it specifically address the APRN? Attention must also be paid to how telemedicine or telehealth is defined. For example, in a state where the definition refers to the "practice of medicine," it is important to review the language in the Nurse Practice Act which defines the scope of practice for APRNs. If the language is not consistent with a state's other telehealth guidelines, the content of the Telemedicine Act may not apply to the APRN.

As valuable members of the healthcare team, APRNs provide quality healthcare in a vast array of settings from primary to acute care. ${ }^{18} \mathrm{APRNs}$ provide physical as well as mental healthcare across the entire lifespan from neonates to geriatric patients. ${ }^{18,19,20}$ With the looming primary care physician shortage and the continued 
growth of the telehealth industry, as well as the shift toward value-based care, APRNs may be called upon to expand the availability of virtual healthcare. This 50-state review demonstrates the wide range of legislative and regulatory findings, and the lack of explicit language in some states with regard to APRN telehealth scope of practice and telenursing. In order to best facilitate APRN adoption of telehealth, state boards of nursing must clearly establish the authority of APRNs to practice via telehealth. A lack of statutory language may dissuade APRNs from performing care via telehealth due to concerns over the legality of providing such care. APRNs practicing in states without clear regulatory guidance should contact their state's board to learn the state's position on telehealth care and APRN practice.

Understanding the state board's interpretation or its lack of statutory language is important. A nurse practice act sets forth the requirements for licensure and establishes the scope of nursing practice. State boards implement the nurse practice act by establishing administrative rules that further define the scope of practice. ${ }^{21}$ Following inquiries about telehealth and APRNs, the board may decide to issue a position statement or advisory opinion to clarify its position. If the board does not consider APRN care via telehealth to be permissible, APRNs may consider pursuing a legislative change. In this case, APRNs may wish to partner with the state chapter of a nursing organization that can provide support and guidance on advocacy efforts, such as the American Association of Nurse Practitioners or the National Association of Pediatric Nurse Practitioners. Consulting national organizations, such as the American Telemedicine Association and the National Telehealth Resource Center, for a given region can also garner support for the advancement of APRN telehealth practice.
Educating state professional boards by utilizing data to highlight the effectiveness and efficiency of telehealth care is of paramount importance. Chen et al. found that using information technology to provide patients access to their lab results, e-prescribing, and e-mail access to providers contributed to a $25 \%$ reduction in patient office visits from 2004 to $2007,{ }^{22}$ thus allowing more visits for patients who needed in person care. Telemedicine has proven effective in treating common childhood illnesses ${ }^{23}$ and improving diabetes self-management ${ }^{24}$; moreover, telehealth has proven to be as effective as in-person visits for patients with asthma. ${ }^{25}$ According to the recent "Report to Congress on Telehealth Utilization and Future Opportunities" by the Centers for Medicare and Medicaid Services (CMS), Medicare beneficiaries in all 50 states and the District of Columbia have received telehealth services, but most have occurred in states with large rural areas. That report also noted that the primary use of telehealth is to provide standard office and outpatient visits, with mental health services being the most common service type. ${ }^{26}$ As the field of telehealth continues to grow, the evidence to support its utilization will continue to expand. Presenting this mounting body of evidence to professional regulatory boards may facilitate a more acceptable view of this method of care delivery for all healthcare providers, especially APRNs.

Furthermore, enacting legislation such as the APRN Compact suggested by the National Council of State Boards of Nursing to expand the ability of APRNs to provide care across state lines ${ }^{27}$ may increase access to telehealth care and facilitate APRN adoption. Most states require a provider to be licensed in the state where the patient is located, with nine states issuing special licenses or certificates related 
to telehealth. ${ }^{12}$ The APRN Compact allows an APRN to hold one multi-state license with the privilege to practice in other compact states. To date, only three states have joined the APRN Compact: Idaho, Wyoming, and ND. According to the National Council of State Boards of Nursing, the Compact will be implemented once 10 states have enacted the legislation. ${ }^{27}$

\section{CONCLUSIONS}

States have disproportionately addressed physician and physician assistant telehealth practice compared to the APRN. Ensuring that telehealth laws, regulations, and policies are inclusive of APRNs will encourage the successful implementation of telehealth programs and excellence in telehealth care that can be provided by APRNs. State licensing boards should provide clarity and promote inclusiveness of all healthcare providers when addressing virtual care regulations. With the current broad variations in telehealth laws by state, APRNs must become fully informed about the legislation and regulations affecting their practice prior to providing care virtually.

Funding statement: There was no funding associated with this project.

Conflicts of Interest: The authors declare no competing interests with respect to research, authorship, and/or publication of this article.

Contributors: Both authors contributed equally to the research, evaluation, and writing of this manuscript.

\section{REFERENCES}

1. Institute of Medicine (US) Committee on Evaluating Clinical Applications of Telemedicine. Evolution and current applications of telemedicine. 1996. Available from: https://www.ncbi.nlm.nih. gov/books/NBK45445/
2. Bureau of Labor Statistics, U.S. Department of Labor, Occupational Outlook Handbook. Available from: https://www.bls.gov/ ooh/healthcare/nurse-anesthetists-nursemidwives-and-nurse-practitioners.htm

3. American Association of Nurse Practitioners Fact Sheet. Available from: https://www.aanp.org/about/all-about-nps/ np-fact-sheet

4. Mehrotra A, Jena AB, Busch AB, et al. Utilization of telemedicine among rural medicare beneficiaries. JAMA. 2016;315(18):2015-16 doi: 10.1001/ jama.2016.2186

5. Darves B. Telemedicine: Changing the landscape of rural physician practice. $N$ Engl J Med. 2013. Available from: https://www.nejmcareercenter.org/article/ telemedicine-changing-the-landscape-ofrural-physician-practice/

6. Henderson K, Davis TC, Smith, M, King M. Nurse practitioners in telehealth: Bridging the gaps in healthcare delivery. $J$ Nurse Pract. 2014;10(10):845-50. https://doi. org/10.1016/j.nurpra.2014.09.003

7. Reed K. Telemedicine: Benefits to advanced practice nursing and the communities they serve. J Am Acad Nurse Pract. 2005;17(5):176-80. doi: 10.111/j.17457599.2005.0029.x

8. National Telehealth Policy. (n.d.). Available from: http://www.cchpca.org/nationaltelehealth-policy

9. South Carolina Code of Laws. Available from: https://www.scstatehouse.gov/code/ t40c047.php

10. Center for Connected Health Policy. Current state laws and reimbursement policies. 2018. Available from: https://www.cchpca.org/ telehealth-policy/current-state-laws-andreimbursement-policies

11. State Policy Resource Center. (n.d.). Available from: http://www. americantelemed.org/policy-page/statepolicy-resource-center

12. Center for Connected Health Policy. State telehealth laws \& reimbursement policies. 2018. Available from: https://www.cchpca. 
org/telehealth-policy/current-state-lawsand-reimbursement-policies

13. Alabama Board of Medical Examiners. Chapter 540-X-15 telehealth. 2014.

Available from: https://www.albme.org/ Documents/Rules/540-X-15.pdf

14. Alabama Board of Nursing. Chapter 610-x-6 standards of nursing practice. 2016. Available from: http://www.alabamaadministrativecode. state.al.us/docs/nurs/610-X-6.pdf

15. North Dakota Board of Medicine. (n.d.). Chapter 50-02-15 telemedicine. Available from: http://www.cchpca.org/nd-rule-boardmedicine-practice-telemedicine

16. Nd.gov. Chapter 43-12.1 Nurse Practice Act. 2018. Available from: https://www. legis.nd.gov/cencode/t43c12-1.html

17. Epstein, Becker \& Green. (n.d.). 50-state survey of telemental/telebehavioral health. North Dakota. Available from: http:// onlinecounselling.com/resources/stateregulations/North\%20Dakota.pdf

18. Stanik-Hutt J, Newhouse R, White $\mathrm{K}$, et al. The quality and effectiveness of care provided by nurse practitioners. JNP. 2013;9(8):492-500. Doi: https://doi.org/10.1016/j. nurpra.2013.07.004

19. Martin-Misener R, Harbman P, Donald $\mathrm{F}$, et al. Cost-effectiveness of nurse practitioners in primary and specialized ambulatory care: A systematic review. BMJ Open. 2015;5(6):e007167. doi: 10.1136/ bmjopen-2014-007167

20. Collins D. Assessing the effectiveness of advanced nurse practitioners undertaking home visits in an out of hours urgent primary care service in England. J Nurs Manag. 2018. doi: 10.1111/jonm.12680

21. National Council of State Boards of Nursing. What you need to know about nursing licensure and boards of nursing.
2011. Available from: https://www.ncsbn. org/Nursing_Licensure.pdf

22. Chen C, Garrido T, Chock D, Okawa G, Liang L. The Kaiser Permanente electronic health record: Transforming and streamlining modalities of care. Health Aff. 2009;28(2):323-33. Available from: http:// content.healthaffairs.org/content/28/2/323.full

23. McConnochie K, Conners G, Brayer A, et al. Effectiveness of telemedicine in replacing in-person evaluation for acute childhood illness in office settings. Telemed J e-Health. 2006;12(3):308-16.

24. Davis R., Hitch A, Salaam M, et al. Telehealth improves diabetes selfmanagement in an underserved community. Diabetes Care. 2010;33(8):1712-17.

25. Portnoy JM, Waller M, DeLurgio S, Dinakar C. Telemedicine is as effective as in-person visits for patients with asthma. Ann Allergy Asthma Immunol. 2016;117(3):241-5.

26. Centers for Medicare \& Medicaid Services. Information on medicare telehealth. 2018. Available from: https://www.cms.gov/ About-CMS/.../Information-on-MedicareTelehealth-Report.pdf

27. National Council of State Boards of Nursing. APRN compact. 2019. Available from: https://www.ncsbn.org/aprn-compact.htm

Copyright Ownership: This is an open access article distributed in accordance with the Creative Commons Attribution Non Commercial (CC BY-NC 4.0) license, which permits others to distribute, adapt, enhance this work non-commercially, and license their derivative works on different terms, provided the original work is properly cited and the use is noncommercial. See: http://creativecommons. org/licenses/by-nc/4.0. 